\title{
Research Experience of the Creative Standpoint Formation of the Novice Comprehensive Secondary School Teacher in Lifelong Vocational Training
}

\author{
Julia V. Ryseva ${ }^{1}$, Milyausha M. Kalashnikova ${ }^{1}$, Pavel A. Baklanov ${ }^{1} \&$ Dmitry O. Zhdanov ${ }^{1}$ \\ ${ }^{1}$ Kazan (Volga region) Federal University, Russian Federation \\ Correspondence: Milyausha M. Kalashnikova, Prospect Mira, 68/19, Naberezhnye Chelny, 423800, Russian \\ Federation. E-mail: milyausha5904@mail.ru
}

Received: June 13, 2014 Accepted: July 23, 2014 Online Published: September 28, 2014

doi:10.5539/ass.v10n20p103 URL: http://dx.doi.org/10.5539/ass.v10n20p103

\begin{abstract}
At the end of the 20th century and in the early 21 st, creativity has been seen to be increasingly important in education. In this paper an attempt is made to present the concept of a novice teacher's creative standpoint in a comprehensive secondary school combining and integrating various educational theories, stances and approaches. The paper concerns different aspects of the creative standpoint such as its nature, background, structure and components.

The paper deals with theoretical and methodological benchmarks of the novice teacher's creative standpoint formation, its structural and substantial characteristics are scientifically proved, program and method support on preserving and further development of the creative standpoint is developed that enriches the theory of the novice teachers' vocational training.

The paper concluded that the creative standpoint represents a system of creative relations, has dynamic character and is of formed quality which can be developed purposefully in a comprehensive secondary school. Development of the given phenomenon is the subjective process which is a part of general development of the novice teacher's personality. Training seminar made a basis for program and method support realization "Effective methods of the creative standpoint forming of the novice teacher in a comprehensive secondary school" and a model of the three-year program "School of the novice teacher". The author innovative programs developed by us have proved that effective formation and development of the novice teacher's creative standpoint is provided with its purposeful, systemic, lifelong character, uniform basic and substantial, humanitarian basis, interdependent and complimentarily character of its theoretical and practical components, novice teachers' equal participation in choosing of goals, content, educational process technologies, psychological and pedagogical help to young specialists in their creative growth.
\end{abstract}

Keywords: creative standpoint, creative attitude, novice teacher, professional pedagogical activity, training seminar

\section{Introduction}

Analysis results of a current state of Russian education testify that there is a variety of problems and contradictions, connected with recruiting of young scholars to school. One of the key problems is the absence of purposeful work with novice teachers, and also effective mechanisms of involving in pedagogical activity that interferes with renovation of educational institution personnel by young specialists (Ryseva, 2006; Vershlovsky, 2008).

The serious factor influencing development of Russian education is that a considerable quantity of pension age teachers remains, with that $30 \%$ of pedagogical high school graduates come to work to school and only $1 / 6$ of novice teachers remains in the education system after first three years of pedagogical activity.

The characteristic and the forecast of the existing problem testifies to necessity of high dynamics of personnel renovation and recognition of novice teachers with the creative standpoint as one of pedagogical values, capable to lifelong professional growth and mobility in a changing world, having knowledge of their own possibilities and professional "self-image" technologies of creative interaction, and also abilities to use the laws of teaching 
and educational process creatively (Zagvyazinsky, 1987; Andreyev, 1996).

In this connection, the concept of the Federal goal-oriented program of education development for 2011-2015 assumes realization of such strategic goals as creation of lifelong learning modern system, training and retraining of personnel taking into account innovative character of Russian education (Russian Federation Government Order of February 7, 2011). Gershunsky fairly notices that any transformations should begin with the system that advances these reforms and pedagogical education innovations, from future teachers' training or in especially extreme and urgent situations-from retraining of experienced teachers (Gershunsky, 2001), that determines an urgency of our research.

It is obvious that the primary goal of higher educational institutions and comprehensive secondary schools must be a formation of the target on creativity, development of the creative standpoint of young specialists as an original method of human existence, forms of self-development and self-affirmation (Kan-Kalik \& Nikandrov, 1990; Shamova \& Ilyina, 2008).

\section{Methodology}

However, the creative standpoint is not considered in researches of a professional teacher's standpoint though there is the data indirectly touching this problem. For example, in Russian literature, attention is paid to general issues of pedagogical creativity development (Zagvyazinsky, 1987; Andreyev, 1996); psychological aspects of preparation for pedagogical activity are considered (Slastyonin \& Podymova, 1997; Mitina, 2004; Shadrikov, 2012).

A great value is acquired by foreign researches. While some researchers have examined the nature of creativity and developed creative pedagogy (Jeffrey \& Craft, 2004), others (Bramwell et al., 2011) have examined creative teachers themselves.

The analysis of such creative and novice teachers' work shows that the main thing in their experience is not a technology (at all its importance), but a special personal standpoint, an original pedagogical philosophy determining behavior and activity of the novice teacher. If the teachers are too conservative and do not want to change their standpoint because of a fear of new innovative approaches (Markova, 1993) and do not want to reconstruct thinking (Asmolov, 1990), they cannot promote school renovation.

In the theory of pedagogical education a standpoint is considered as an integral part of pedagogical culture (Bondarevskaya, 1999), professional competence (Markova, 1993; Vershlovsky, 1998), as a necessary condition of pedagogical activity realization (Abulkhanova-Slavskaya, 1980; Kulnevich, 2001).

The scientists (Vershlovsky, 1998; Shamova \& Ilyina, 2008) name reconsideration of own actions as one of the basic mechanisms of the standpoint formation. That is humanization process at modern school assumes formation of the professional standpoint of each teacher, at the same time awareness acts as one of the major characteristics of the teacher's standpoint.

Subjectivity of the pedagogical standpoint as realization of subject of pedagogy when a person is a creator of a person is considered in some research works (Amonashvily, 1990; Serikov, 1999). They consider that the subject standpoint of the teacher provides formation of a person in a whole, but not just his individual parts.

The standpoint as a role position (Kon, 1984; Maralov, 2002) and as integration of dominating selective relations (Kodzhaspirova, 2005; Myasishchev, 2005) is formed through individual and group search, emotional experiences and residing of significant senses.

The standpoint is also considered in a context of such concept as the status since diverse personal standpoints transform it and at the same time are constructed on the basis of the status (Parsons, 2000; Ananyev, 2001; Park, 2011).

Koof et al. (2007) stated that teacher's creative process emerged from the interaction between their personal characteristics, including personal intelligences, motivation, values, and the communities in which they worked and lived; Craft et al. (2008) explored the nature and the relationship between creativity, wisdom and trusteeship in education.

It is underlined that the link of determination "personal standpoint" with such diverse terms as valuable orientation, vital orientation, system of relations, sense and value interpenetration, stability dynamics notifies that we talk about one general centre of spiritual development of a person (Ananyev, 2001).

Discussing creativity issues, Andreyev (2008) confirmed that when we speak about pedagogical creativity we mean humanity and humanism which are determined first of all by a vital standpoint of a teacher, and his personal creative concept. 
The results of analysis of long-term researches by Ananyev (2001) and Brushlinsky (2003) have shown that it is necessary to measure true value of the standpoint by a creative contribution to social development. We designate such standpoint as creative.

The undertaken analysis of theoretical approaches allows us to treat standpoint formation as the individual self-determination including not only self-knowledge (discovering by the novice teacher of his measure of reality, professional mission, awareness of his role in a whole), but also a self-estimation (orientation on the objects demanding adjustment of potential reserves of the creative growth), self-forecasting (a method of psychological, creative self-orientation), self-reflexion (understanding of professional activity) as an interconnected preconditions of creative standpoint dynamics.

\section{Results}

Having analyzed questionnaires of the novice teachers during our empirical research, we come to following conclusions. Novice teachers have a weak idea about the content of a concept "a creative standpoint". The majority of respondents are limited to the generalized answers, considering this phenomenon as a number of separately conducted creative events and tasks. In none of the determinations given by young specialists such concepts as "relation", "belief system", "point of view" have not been specified. Careful study of this problem allows asserting that novice teachers see sense of the professional activity in transfer of social and cultural experience to rising generation while modern treatment of a teacher's profession assumes "life creativity". The essence of "life creativity" is valuable and notional, creative interpersonal interaction of participants of the educational process, providing their simultaneous creative self-development, self-realization and self-improvement (Andreyev, 1996).

In this connection it is very important to formulate theoretical and practical justification of psychological and pedagogical ways, providing effective creative standpoint formation of the novice teacher, and also to develop program and method support on its maintenance and further development.

Designing the program on the creative standpoint formation of the novice comprehensive secondary school teacher, we have noticed its conformity of the standard model offered by Koziev (1987). For a creative standpoint formation of the novice teacher it is necessary to define: 1 . value problem; 2 . motivational problem (an image of a desirable future); 3. Technological problem.

In our study we assume the value problem as theoretical justification of the basic concepts of research, assessment of the level of formation of the creative standpoint. We allocate three levels of the creative standpoint formation of the novice teacher: optimum, satisfactory, unsatisfactory. Determining the creative standpoint level of the novice teachers it would be reasonable to use the following criteria: activity, intellectual and criterion of relations. The motivational problem has been embodied in meaningful and formulated purposes, tasks, hypothesis, object and subject of research, ideal model of a teacher.

The decision of technological problem is presented in the training seminar program "Effective methods of the creative standpoint forming of the novice teacher in a comprehensive secondary school" and a model of the three-year program "School of the novice teacher".

The training seminar program "Effective methods of the creative standpoint forming of the novice teacher in a comprehensive secondary school" is structured in accordance with the block-modular principle:

1) Psychological and educational diagnostics methods of the novice teacher creative standpoint formation and development.

2) The training seminar introduction (motivational and "warming up" procedures) includes the definition of the content, purposes and objectives of the training seminar; rules for group working.

3) The section "Realization of personal characteristics and self-concept optimization" is devoted to the work on the content of "self-image", which is one of the most important social sets for novice teachers.

4) In the section "Self-concept in pedagogical communication and the optimization of the relationship to the participants of the educational process" particular attention is given to the young teacher's involvement in public relations during the creative communication process, integrating them as personally significant.

5) The section "Self-concept in pedagogical communication and the optimization of the relationship to creative pedagogical activity" focuses on the definition of self-position, activity management, behavior and thinking in accordance with the supreme values; personality development, i.e. self-development.

6) The concluding block includes the final creative project of the group. 
Thus, there is an opportunity for reflection, introspection, exploration and individual ways of professional standpoint growth, personal role repertoire. And the result of professional communication in the training seminar is a creation of the active personal standpoint of the participants, the standpoint that is becoming the basis for self-education.

Our training seminar lessons were visited by 154 young teachers. Significant confirmation of productive co-creative activity during the training seminar based on the results of designed questionnaires and forms is the following: the optimal level displacement of the creative standpoint of the novice teachers varies from $5 \%$ to $11 \%$, a satisfactory level from $42 \%$ to $54 \%$, insufficient from $53 \%$ to $35 \%$.

The three-year program "School of the novice teacher" was designed in connection with the necessity and the possibility of purposeful development of the creative standpoint of the secondary comprehensive school young teachers (Ryseva, 2009). Program and methodological support includes: diagnostics capabilities, novice teacher's abilities to pedagogical creativity (questionnaires, forms, reflection of the novice teachers' educational activities, the need for creative self-development, self-realization, self-improvement); support and assistance to novice teachers in selecting individual developmental trajectories (agreement of participants' aims in the educational process; discussion of priority issues, school and teachers' development; accounting factors affecting the formation of the creative standpoint; expanding the system of internal and external motivation); assistance in the formation, development and maintenance of the creative standpoint of the young teachers (trusteeship of an experienced tutor, co-creative and research activities, exchange of experience, games arrangement, lectures, discussions, implementation of micro studies, participation in competitions, conferences, creative projects, "brain-storming", trainings, reflexive analysis of teaching activities, mutual planning of further professional self-development of the secondary comprehensive school novice teachers).

Analysis obtained by the methods of operative data measurement (questionnaires, observations, interviews, introspection and self-esteem, self-analysis of young teachers) shows the presence of high interest and emotional involvement of the young teachers in the given work forms. The growth of communicative competence, deep self-perception and understanding of group members, persistent changes of professional self-consciousness, mastering of norms and ways of collective life, the emergence of multiple interpersonal relations, conscious possession of restructuring techniques of personal and professional standpoints in the creative collaboration with the educational team, colleagues and parents is evident.

Experimental research data allowed to determine the effectiveness degree of the proposed model of the young teachers' creative standpoint formation on the basis of generalized efficient and personal indicators related to results of activity, both of the novice teachers and their students: the positive dynamics of the educational process (positive dynamics of performance and quality of training, student achievement in the subject competitions, conferences, project and research works), based on the level of perfection of the novice teacher's pedagogical skills (participation of the young teachers in professional competitions at various levels), research activities (defense of Ph.D. thesis in pedagogy and psychology), the satisfaction degree of professional and creative self-development and methodological quality, research works.

\section{Discussion}

The essence of the creative standpoint is to implement creative ideas. This process will be more productive if a novice teacher masters the technology of forming a creative standpoint fully and successfully and is able to self-knowledge, self-esteem, self-prediction, and self-reflection. The personal standpoint primarily expresses his attitude. The concept of the attitude is not only a subjective opinion, but it is considered in the key of relationships with other people and the environment, and also the result of interaction of a person with his own life. Consequently, the novice teacher's creative standpoint can be determined not only as a point of view, but also as a system of creative attitudes to teaching, to himself and others in the educational process. In the system of creative relationships the young teacher characteristics, ways of modeling life and valuable characteristics of different spheres of life, personally and professionally meaningful, are formed. We can conclude that a creative standpoint is not just a set of relations, but a character of their realization, which determines the future way of life-professional and personal.

Personal standpoint is personally accepted and not imposed by the external environment choice of his place in life, mediated by internal motives. It means that a novice teacher should not be considered in terms of "qualitative" set, but in terms of directivity, teaching philosophy, professional interests, beliefs, motivations, values, etc., that will generate a creative standpoint, despite the lack of experience, immaturity of some professional qualities (Cremin et al., 2006). Orientations stabilize the novice teacher's standpoint, but such stabilization can be called only conditional because each individual situation activates a new theme, moving the 
entire chain of motivation, which eventually the standpoint of the teacher reacts on. That is, on the one hand, the creative standpoint, being the core of the novice teacher's culture, acts as a fundamental of principles that does not change and is not distorted in certain favorable and unfavorable situations and conditions. On the other hand, the standpoint dynamics fixes the transition into a new state. For example, experts believe (Vershlovsky, 1998; Shadrikov, 2012), that the novice teacher's creative standpoint will provide an opportunity to master teaching creative activities, despite of some professionally significant qualities that are temporarily absent. It means that variability and mobility are objective characteristics of the creative standpoint.

Hence the obvious conclusion is that the attitude to the profession is a dynamic property, as it arises and rebuilds at various stages, in different situations. It is known that in human behavior, including professional, human dependence on the situation presupposes some internal self-determination. That is an attitude to the profession which acts as an internal conscious catalyst of external influences, as a measure of personal responsibility for decisions and implementation of the social function of the profession, acting as a regulator of professional behavior. This internal self-regulation mode, when the novice teacher is searching for his standpoint validation, helps to implement selective activities.

Being an integral personality characteristic, the novice teacher's creative standpoint is a united formation of two inseparable parts of teaching activities: personal and professional, i.e. it serves as an indicator of personal development and the young teacher's availability to creative professional activity.

By the creative standpoint we understand a complex personal formation expressing a system of creative, intellectual, volitional and emotive relations to the world, society, people, and himself, to standards, regulations, rules, in particular to the pedagogical reality and educational activities-to all what is a sphere of creative teacher's interaction with the social and natural environment and is the source of his creative activity.

The structure of the novice teacher's creative standpoint includes the following components: a) a creative attitude of the novice teacher to himself, suggesting his willingness and ability to lifelong creative, spiritual, intellectual, physical self-improvement and particularly to professional development; $b$ ) creative relationships with others, willingness and ability to provide a subject-subject creative interaction with students, colleagues, parents, representatives of society, who are related to students; c) a creative attitude to teaching on the principles of activity, unity of practice, research and creativity. We determine the creative standpoint not as the sum of these components, but as an open system, where they are closely connected, interdependent and strongly influence each other providing the evolutionary nature of the system as a whole.

The analysis allowed to conclude that the young teacher's creative standpoint formation is primarily a dialogic subject-subject (developing) strategy for creative interaction between the participants of the teaching process based on the self-awareness, self-reflection, self-esteem, self-prediction mechanisms and directed at redefining of standpoints, interchange and mutual enrichment of value-semantic spheres, qualitative change in activities, behavior, results.

\section{Conclusion}

Being a central element in the process of young teacher's self-knowledge and self-awareness, the creative standpoint is a quality that can be formed and should be an integral and key feature of the novice teacher's personality.

We have proved that the purposeful development of the novice teacher's creative standpoint in a relatively short time can be achieved by the training seminar "Effective methods of the creative standpoint forming of the novice teacher in a comprehensive secondary school" which involves the selection of content units, the use of "role-playing" game images submitted as the teachers' professional standpoints in situations of pedagogical communication. Training seminar classes showed that the creative standpoint is a means of preserving and strengthening novice teachers' creative relationship to their activities, to themselves and to other members of the educational process.

Subsequent formation, development and preservation of the novice teacher's creative standpoint are carried out in the pedagogical model "School of the novice teacher" based on the concept of creative self-development, self-actualization, self-improvement and self-education. "School of the novice teacher" model proved that within a comprehensive secondary school various in content and educational functions communication of novice teachers, their colleagues and students, promoting enrichment of professional and humanitarian culture, and a development-oriented creative standpoint can be organized.

The prospects of our study are seen to develop a formation model of innovative thinking and creative standpoints of different categories of teachers (from novice to experienced), to reveal the creativity of teachers in terms of 
their impact on individuality of students; develop forms and methods of training for teachers without departing from their professional activity; develop author innovative programs in teaching pedagogical creativity.

\section{References}

Abulkhanova-Slavskaya, K. A. (1980). Activities and personality psychology (p. 334). Moscow: Nauka.

Amonashvily, Sh. A. (1990). Personal and human basis of pedagogical process (p. 559). Minsk: Universitetskoye.

Ananyev, B. G. (2001). About the problems of modern human science (p. 272). St. Petersburg: Piter.

Andreyev, V. I. (1996). Pedagogics of self-development. Innovative course (p. 552). Book 1. Kazan: KFU Publishing.

Andreyev. (2008). Heuristics for creative self-development (p. 224). Kazan: Innovation Centre.

Asmolov, A. G. (1990). Personality psychology (p. 367). Moscow: MSU Publishing.

Bondarevskaya, Y. V. (1999). Pedagogical culture as public and personal value. Pedagogics, 3, 37-43.

Bramwell, G., Reilly, R., Lilly, F., Kronish, R., \& Chennabathni, R. (2011). Creative Teacher. Roeper Review, 33(4), 228-238. http://dx.doi.org/10.1080/02783193.2011.603111

Brushlinsky, A. V. (2003). Psychology of the subject (p. 272). St.Petersburg: Aleteya.

Craft, A., Gardner, H., \& Glaxton, G. (2008). Creativity, Wisdom, and Trusteeship: Exploring the Role of Education (p. 181). London: SAGE Publications.

Cremin, T., Burnard, P., \& Craft, A. (2006). Pedagogy and Possibility Thinking in the Early Years. Thinking Skills and Creativity, 1(2), 108-119. http://dx.doi.org/10.1016/j.tsc.2006.07.001

Gershunsky, B. S. (2001). Education as religion of the third millennium: Harmony of knowledge and faith (p. 128). Moscow: Pedagogical society of Russia.

Jeffrey, B., \& Craft, A. (2004). Teaching creatively and teaching for creativity: Distinctions and relationships. Educational Studies, 30(1), 77-87. http://dx.doi.org/10.1080/0305569032000159750

Kan-Kalik, V. A., \& Nikandrov, N. D. (1990). Pedagogical creativity (p. 144). Moscow: Pedagogics.

Kodzhaspirova, G. M. (2005). Pedagogical anthropology: Education guidance (p. 287). Moscow: Gardariky.

Kon, I. S. (1984). In search of itself: Personality and consciousness (p. 151). Moscow: Politizdat.

Koof, J., Chen, C., Himsel, A., \& Greenberg, E. (2007). Values and creativity. Journal of Creative Behavior, (19), $105-122$.

Koziyev, V. N. (1987). Formation of professional qualities of the identity of a teacher (p. 15). Leningrad: Znaniye.

Kulnevich, S. V. (2001). Pedagogics of the personality: From concepts to technologies (p. 159). Rostov-on-Don: Uchitel.

Maralov, V. G. (2002). Self-knowledge and self-development bases (p. 256). Moscow: Akademiya.

Markova, A. K. (1993). Psychology of a teacher's work (p. 192). Moscow: Prosveshcheniye.

Mitina, L. M. (2004). Psychology of work and professional development of a teacher (p. 320). Moscow: Academiya.

Myasyshchev, V. N. (2005). Psychology of relations (p. 158). Moscow: MPSI.

Park, R. (2011). Chosen sketches: Collection of translations (p. 320). Moscow: RAN INION.

Parsons, T. (2000). About the structure of a social action (p. 880). Moscow: Akademichesky proekt.

Russian Federation Government Order. (2011, February 7). \# 163-r "On the Concept of the Federal target program of education for 2011-2015". Retrieved October 8, 2012, from http://www.garant.ru/products/ipo/prime/doc/55070647

Ryseva, J. (2006). About the problems of modern teachers of secondary schools. Problems of theory and practice in modern specialist training. NGLU Publishing, (4), 272-279.

Ryseva, J. (2009). Realization of pedagogical model of the program "School of the novice teacher". Herald of Pomorsky University, 7, 315-318. 
Serikov, V. V. (1999). Education and personality. Theory and practice of educational systems design (p. 272). Moscow: Logos.

Shadrikov, V. D. (2012). Quality of pedagogical education (p. 200). Moscow: Logos.

Shamova, T. I., \& Ilyina, I. V. (2008). Technology of management of the teacher's subjectivity development in the conditions of educational institution. Theory and practice of realization of the competence-based approach in managing the development of educational process subjects. Prometey, (5), 133-148.

Slastyonin, V. A., \& Podymova, L. S. (1997). Pedagogics: Innovative activity (p. 224). Moscow: Magistr.

Vershlovsky, S. G. (1998). A teacher about himself and profession (p. 385). St.Petersburg: Znaniye.

Vershlovsky, S. G. (2008). Lifelong education. Historical and theoretical analysis of the phenomenon (p. 151). St.Petersburg: StPAPPO.

Zagvyazinsky, V. I. (1987). Pedagogical creativity of a teacher (p. 159). Moscow: Pedagogics.

\section{Copyrights}

Copyright for this article is retained by the author(s), with first publication rights granted to the journal.

This is an open-access article distributed under the terms and conditions of the Creative Commons Attribution license (http://creativecommons.org/licenses/by/3.0/). 